\title{
Exploring heterogeneous grouping strategies from the learning analytic perspective
}

\author{
Jingyun Wang *, Kentaro Kojima *
}

\begin{abstract}
In this paper, we present a mathematical model for forming heterogeneous learning groups under different teaching goals. This model requires a formulation which can effectively predict the learning performance of cooperative learning groups. Therefore, we explore the correlations between learning performance and various learner characteristics including learning motivation, learning strategy use, learning styles and gender based on real-world data. By means of analyzing learner data of 157 students in a cooperative learning course, learner attributes irrelevant to cooperative learning performance are excluded from the formulation; this sharply decreases the workload of group formation calculation. In future work, a tool will be implemented based on the adjustable mathematical model and this tool will be used in daily teaching to evaluate its effectiveness.
\end{abstract}

Keywords: Group formation; cooperative learning, heterogeneous, learning analytics.

\section{Introduction}

The potential benefits of learning through group collaboration, such as attitude improvement [1], better understanding of knowledge through discussions [2][3], social skills development [4], and so on, have been well documented in the academic literature. For designing a collaborating learning scenario, group formation is a critical process. The traditional group formation strategies that cause little effort of instructor are random [5] and self-organized [6]. However, those strategies cannot guarantee all the groups achieve expected learning goals. Especially when a group does not have any learner with required skill, knowledge, or motivation addressing the task, it is difficult to generate meaningful interaction among peers and often lead to poor group outcomes. On the other hand, in a well-structured learning group, through meaningful interaction learners can share their idea and develop new requisite skill spontaneously and collaboratively [7] [8] [9]. Therefore, to enable meaningful interactions among group members and promote effective collaborative learning activities in all the groups, group formation by considering various learner attributes in the class is a fundamental and essential step.

Previous researches [5] [7] [8] [9] [10] [11] [12] [13] have studied group formation problem from both theoretical and practical point of views. There are at least three issues when one tries

\footnotetext{
* Kyushu University, Fukuoka, Japan
} 
to find appropriate grouping strategy with consideration of learner attributes. First, it should be determined which learner attributes is relevance to the accomplishment of the learning goals. The selection of learner attributes depends on purpose and tasks of collaborative learning. It should be noted that although variety of members' attributes affect group performance, it is not clear that which kind of composition of learner attributes can maximize group performance. This leads to the second issue -- the definition of goodness of formed groups in a class.

Typical definition of the goodness of a group relates to heterogeneity or homogeneity of attributes of group members. Studies propose strategies with the main goal of obtaining homogeneous groups [14], insist on the hypothesis that group members can generate meaningful interaction if their attributes locate in the same or similar level; studies propose strategies with the main goal of obtaining heterogeneous groups [10] [15], insist on the hypothesis that individual differences inside a group encourage better meaningful interaction. Homogeneous grouping supporters claims that lower ability members benefit from the respect in a homogeneous group instead of having the high possibility of being isolated from advanced peers in a heterogeneous group [16], and learners construct their behavior model better after interacting with similar ability learner who shows great learning performance [14]. Moreover, compared to homogeneous groups, there could be more serious conflict in heterogeneous groups because of critical individual differences [17]. On the other hand, heterogeneous grouping supporters point that homogeneous grouping damages not only low-ability learners due to their exposure to lowered expectations and reduced resources [18], but also high-ability learners who are usually the affluent children due to no opportunity to learn the virtues of assisting others [19]. They claim that peer interactions among diverse learners enable them to gain the development of social competence [20] and produce more outcomes by assisting others to overcome cognitive obstacles [21] [22] [23]. However, the relation between goodness of a group and attributes of group members is complex and task-depended.

Even after determining hypothesis on goodness of a group, finding good grouping candidates, is still quite difficult since numbers of possible grouping candidates increase as factorial. This is the last but no least issue of group formation, which involves not only goodness of each group but goodness of all the groups inside a class. For solving this NP-hard problem, several studies have proposed to find optimal grouping solutions using heuristic approaches [7] [8] [9] [10] [11]. To evade low-performance groups, Moreno et.al propose genetic algorithm grouping strategy for achieving inter-homogeneous groups and intra-heterogeneous members in each group [8]. For instances, for collaborative programming tasks which consider programming skill and knowledge as relevant learner attributes, intra-heterogeneous standard means that the goodness of a group is increased when heterogeneity of skills and knowledge are increased in a group. Furthermore, inter-homogeneous standard means that the goodness of grouping is increased when variance of goodness of groups in a class is decreased. Even though, large number of attributes still causes a heavy workload for finding optimal grouping solution. Without any real-world data analytics support, the effectiveness of grouping approach can decrease by taking irrelevant learner attributes into account. Moreover, in real-world situations, the measurement for learner characteristics has limit accuracy and the calculation is time-consuming also especially while dealing with a large number of students. All of those required the examination of the relation between the learner attributes and group performance.

In order to develop students' collaborative and communication skills, since 2014 Kyushu university of Japan requires all the first-year undergraduate students to take a one-year course call "Interdisciplinary Collaborative Learning of Social Issues". One unit of this curriculum requires three professors to form one team and come up with one topic which consists of 3 subtopics. In 2016, 18 topics were provided in the first semester and another 18 topics in the 
second semester for around 2900 freshman of various majors. Students can choose their interested topics at the beginning of each semester, but each topic only can be chosen by around 160 students. After deciding the topic, every 4 weeks ( 3 hours per week), one subclass of around 50 students will be divided into small groups and then those groups will complete tasks towards one subtopic guided by one professor with the support of learning management system Moodle (e-book and e-portfolio systems are also used by some professors) until they complete all the tasks of three subtopics.

In this course, how to decide grouping of students to maximize the learning performance is always one of the tough and complicated issues of professors. Since the instructors need to decide the grouping at the first week of this course, it is difficult to find the optimal solution in this limited time, therefore, in practice, instructors usually adopt a random-assignment strategy (provided by Moodle) to form learning group or ask students to form groups by themselves. Those situations sometimes lead to some poorly-constructed groups that demotivate group members and cause their resistance to group work or hinder the learning process.

In fact, using Moodle system, not only individual reports and group assignments can be easily collected for marking, but also various questionnaires can be distributed for collecting the data related to learner characteristics. Those educational big data recorded in Moodle enable us to explore grouping approaches with the support of data analysis. In this paper, we intend to discuss the group formation problem by analyzing the group composition of learning characteristics (including learning motivation, learning strategy use, learning style and gender) and exploring their relations with learning performances (including individual report, individual presentation, and group assignment scores). The data for analysis in this paper involve the learner data of 157 students who completed the tasks of one subtopic called "learning space design" (belonged to topic "space" which includes 3 subtopics of "learning space design", "psychology space investigation" and "living space design") for 4 weeks. As shown in Figure 1, the previous strategies that decide group formation directly based on the heterogeneity or/and homogeneity of attributes of group members; in contrast, at first, we reveal the relation between learner attributes and group performance by learning analytics, and then use the formula suggested by the learner data to decide the grouping candidates.

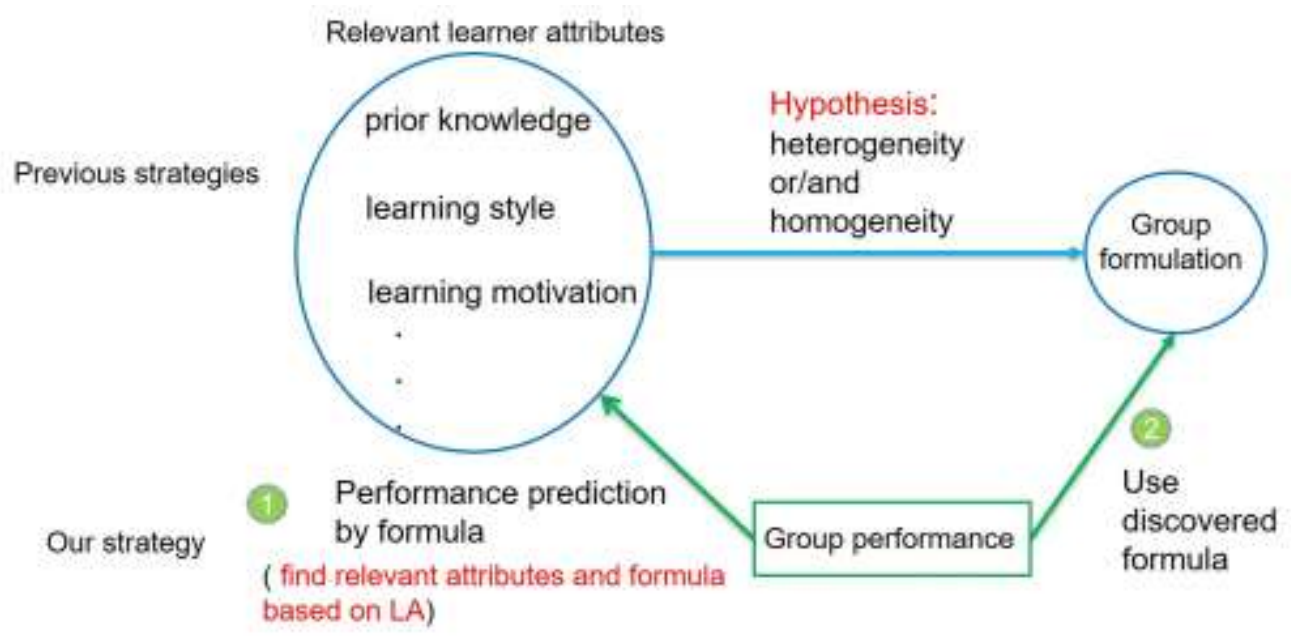

Figure 1: Our strategy contrast to previous ones 
The remainder of this paper is structured as follows: Section 2 introduces the tools for measuring learner characteristics in this research; Section 3 discusses the correlation between the leaner characteristics and learner performances and identifies those who related to learner performances; Section 4 presents an approach to predict group performance by analyzing those relevance attributes; finally, the conclusion and the direction of the further work are provided in Section 5.

\section{Measurement Techniques for Learner Characteristics}

Since the goal of the target course is the development of collaborative and communication skills through the completion of the "learning space design" task, learning motivation, learning strategy use, learning style and gender are the relevant learning attributes need to be measured.

\subsection{Learning Motivation and Learning Strategy Questionnaire}

Learning motivation is the internal drive that enables a learner to strive to study and get new skills. If a learner can find a way or ways to keep himself motivated, he may expend more effort on the leaning activity and have more possibility to carry out his actions to the best of his abilities. In this study, we use the motivation questionnaire written in Japanese included 27 items designed based on the measure tools of Pintrich et al. [24] with some modifications. The items related to test anxiety in the original version were not included in this questionnaire since the target course does not have any test. Students were instructed to respond to each item on a 7-point scale (1-3: strongly to slightly disagree, 4: neither agree nor disagree, 5-7: slightly to strongly agree) at the third week. A factor analysis was performed on all the collected 157 responses towards the 27 items. On the basis of the results, four scales were constructed: perceived self-efficacy $(7$ items, $=0.886)$, perceived intrinsic value $(6$ items, $=0.902)$, use of retrieval strategy for the course tasks ( 6 items, $=0.802$ ), use of knowledge assimilation strategy and effort management strategy ( 5 items, $=0.795$ ), accounting for $60.2 \%$ of the total variance. Two items were excluded from the scales because of a lack of correlation. In all the calculations of this paper, the mean of the items in a scale will be used to represent the ranking of that scale.

The scale of self-efficacy was constructed by the responses to the following 7 items. The numbers in front of the item descriptions reflect the items' actual position on the questionnaire. Self-Efficacy refers to students' beliefs that they are able to perform the task [24].

1. Compared to other students in this class, I think I learn quiet well.

5. I think I do well in this class.

7. Compared with others in this class, I think I am a good student

9. I am sure I can do an excellent job on the problem and tasks assigned for this class

11. I think I receive a good grade in this class.

14. My study skills are excellent compared with others in this class.

17. Compared with other students in this class I think I know a great deal about the subject.

The scale of the perceived intrinsic value of the course was constructed by the responses to the following 6 items. Perceived intrinsic value refers to student's goal for the task and their beliefs about the value and interest of the task [24].

4. It is important for me to learn what is being taught in this class.

6. I like what I am learning in this class.

8. I think I will able to use what I learn in this class in other classes

15. I think that what I am learning in this class is useful for me.

18. I think what we are learning in this class in interesting. 


\section{Understanding this subject is important to me.}

The scale of use of knowledge retrieval strategy related to the course tasks was constructed by the responses to the following 6 items. Knowledge retrieval strategy in this paper refers to the strategy used for retrieving the knowledge from the brain.

10. Although it will be tough, I would choose the topic that I can learn something from.

12. Even I got a low score on a report, I will try to learn from my mistakes.

13. When I do a task, for submitting a good report, I normally try to recall what the professor said in the class.

19. I will try to figure what the teacher is saying even I do not understand at the beginning.

21. When studying, I copy my notes over for remember what is taught.

23. I used what I learned from my previous homework assignments to do the new assignments.

The scale of use of knowledge assimilation strategy and effort management strategy was constructed by the responses to the following 5 items. Knowledge assimilation strategy in this paper refers to the strategy such as planning (item 24), summarizing (item 25), paraphrasing (item 16) and comparing with related things (item 27) to promote the knowledge assimilation. Effort management strategy refers to students' persistence at on difficult or boring tasks (item 26).

16. When I study, I put important idea or items into my own word.

24. Before I start my assignments, I will investigate the necessary things

25. When I am studying a topic, I will try to understand by making all the contents together

26. If I don't like what is taught in the class, I will still work hard to get a good grade.

27. When reading a material, I try to connect the things I am reading about what I already know.

Table 1: The correlation among perceived motivation and beliefs and the use of learning strategies

\begin{tabular}{|c|c|c|c|c|}
\hline Variables & 1 & 2 & 3 & 4 \\
\hline 1. Self-efficacy & - & & & \\
\hline 2. Intrinsic value & $0.512^{* *}$ & - & & \\
\hline 3. Retrieval strategy & $0.448^{* *}$ & $0.565^{* *}$ & - & \\
\hline $\begin{array}{l}\text { 4. Assimilation and effort } \\
\text { management strategy }\end{array}$ & $0.461 * *$ & $0.541 * *$ & $0.666^{* *}$ & - \\
\hline Mean & 4.03 & 4.75 & 4.91 & 4.95 \\
\hline SD & 1.00 & 1.11 & 0.84 & 0.89 \\
\hline
\end{tabular}

Table 1 displays the result of the correlation analysis among perceived motivation beliefs and the use of learning strategies. The result suggests higher level of retrieval strategy use were correlated with higher level of self-efficacy $(r=0.448)$ and intrinsic value $(r=0.565)$; higher level of assimilation and effort management strategy use were correlated with higher level of self-efficacy $(\mathrm{r}=0.461)$ and intrinsic value $(\mathrm{r}=0.541)$.

\subsection{Learning Style Model}

There are over 70 learning style models in the literature [25]. Different models are used by various studies to classify learners into supposedly distinct groups or to assign learners graded scores on single or multiple dimensions [26]. In this study, we focus on the widely-adopted 
Felder-Silverman learning style model (FSLSM) which carefully formulates the active-reflective differences that are related to the cooperative learning.

Four dimensions of learning style are defined in FSLSM: Active/Reflective, Sensing/Intuiting, Visual/Verbal, and Sequential/Global. The first dimension is about information processing: learners of active scale tend to understand the knowledge through active trial, discussion or by explaining it to others while learners of reflective scale tend to observe reflectively. The second dimension involves information perception: learners of sensing scale prefer to perceive data by the senses while learners of intuiting scale prefer by accessing memories or insights. The third dimension refers to information reception: visual learners prefer that information is presented by diagrams, flow charts, pictures or films rather than in written words, which is preferred by verbal learners. The last dimension involves information understanding: sequential learners gain understanding in logically linear steps while global learners need the big picture of a subject before mastering details. It is worthy to notice that "these four dimensions have not been shown to be fully independent" [27].

In this study, to assess the cognitive styles of the participants, we use a questionnaire written in Japanese, translated from the Index of Learning Styles (ILS) of 44 questions in the class of the second week. The ILS is the instrument designed based on FSLSM and its current version was suggested to be reliable, valid and suitable for capturing learners' behavioral tendencies [28] [29]. According to Felder and Spurlin [28], each learning style dimension has associated with 11 force-choice items, with each option ( $a$ or b) corresponding to one or the other category of the dimension (such as active or reflective). Based on the analysis result, the internal reliability performed on the (a) items in each scale for all 157 valid ILS questionnaires is as followed. Active/Reflective: 0.520; Sensing/Intuiting: 0.501; Visual/Verbal: 0.534; Sequential/Global: 0.403. As it is found in many previous researches [29] [30] [31] [32], the weakest reliability was found in Sequential/Global scale. Except Sequential/Global scale, the rest of other scales' resulting coefficients meet acceptable limits (higher than 0.5 ) as suggested by Tuckman [33]. The further investigation shows there were 5 out of 11 items in this scale which were not accurate enough due to improper translation form English to Japanese. We fixed these improper translations for the next semester and in future work the new Japanese version of ILS will be used to replace the older one.

\section{Analysis on Learning Performance}

At the first week of the target course, 5 or 6 students were assigned into a group and required to work together on open-end tasks since then. At the first three weeks, each group was required to submit a report through the Moodle system immediately after the class (in total 3 reports, with perfect scores of 5,10, and 40, respectively). At the beginning of the forth week, every student had to evaluate the contribution of their peers in the same group to the group work towards 5 items on a 7-point scale. Therefore, each group member had an individual contribution factor (ICF). For a group of learners $\left\{\mathrm{P}_{1}, \mathrm{P}_{2}, \ldots, \mathrm{P}_{\mathrm{m}}\right\}, \mathrm{ICF}_{\mathrm{P}}=\mathrm{N} \times \sum_{j}^{m} \mathrm{G} S_{i j} / \sum_{i}^{m} \sum_{j}^{m} \mathrm{G} S_{i j} \quad(i \neq j)$, where $\mathrm{GS}_{\mathrm{ij}}$ represent the score that the leaner $\mathrm{P}_{\mathrm{i}}$ received from another learner $\mathrm{P}_{\mathrm{j}}$. Individual Score for group report was calculated by ICF $\times$ (sum of group report scores). At the final week, students were assigned to a Jigsaw group [34] and each of them had to make a presentation about their third report for students in other groups. Figure 2 shows an example of a class of 50 students which at the first week is divided into 10 working groups. Then after 3 weeks of cooperative work each member from these 10 groups is assigned into a Jigsaw presentation group to explain their works to member from other groups. After the presentation, each student received the 
evaluation (with a perfect score of 40) from the audiences. The individual presentation score was the mean score given by the audiences. Finally, every student had to make a report (with a perfect score of 5) about this presentation event to describe what they learned from other presenters and how can they improve their own group design. In summary, each student had three individual performance indexes: one for the contribution in group work, another for the presentation, and the other for final report. Two major research questions are discussed based on the analysis of learner data involving these three indexes.

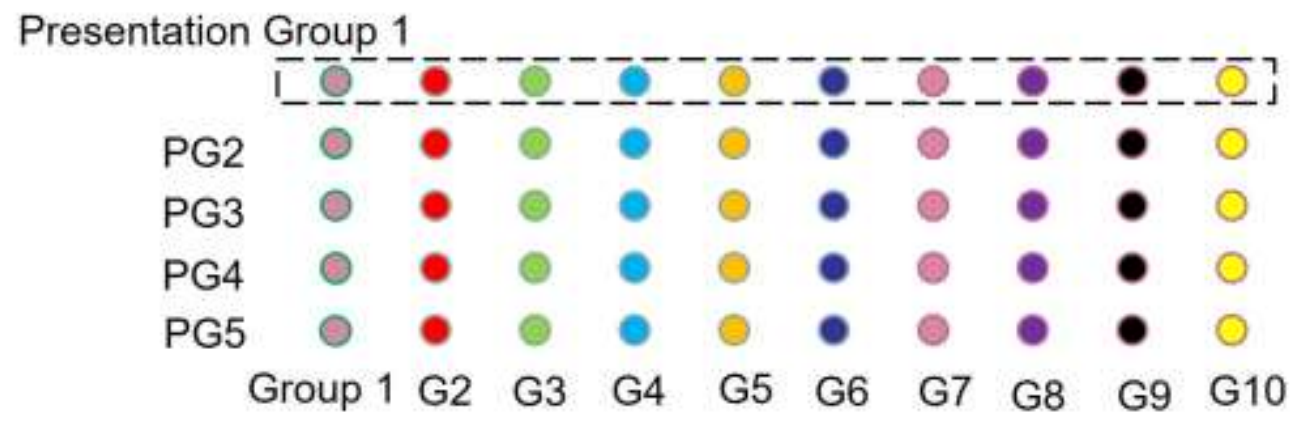

Figure 2: A group distribution example of a class with 50 students

\subsection{Direct Factors of Individual Performance}

The first research question concerns how the learner attributes (including the motivation and learning strategy scales, and learning style scales) were related to individual performance in the cooperative course. Table 2 displays the result of the correlation analysis among the rankings of motivation, learning strategy variables, learning styles, and the individual performance.

Table 2: The correlation among learner attributes and individual performance

\begin{tabular}{|c|c|c|c|c|}
\hline Performance & & Score for group work & Presentation & Report \\
\hline \multirow{2}{*}{ Attributes } & Mean & 44.94 & 32.03 & 3.88 \\
\hline & SD & 8.41 & 2.63 & 0.93 \\
\hline \multirow{2}{*}{ Belief } & Self-efficacy & $0.226^{* *}$ & $0.254 * *$ & 0.131 \\
\hline & Intrinsic value & $0.247 * *$ & 0.128 & -0.015 \\
\hline \multirow[b]{2}{*}{ Learning strategy } & Retrieval strategy & 0.114 & 0.053 & 0.099 \\
\hline & $\begin{array}{l}\text { Assimilation and } \\
\text { effort management } \\
\text { strategy }\end{array}$ & $0.200 * *$ & 0.069 & 0.119 \\
\hline \multirow{4}{*}{ Learning styles } & Active & 0.064 & $0.247 * *$ & -0.088 \\
\hline & Sensing & 0.041 & 0.007 & $0.271 * *$ \\
\hline & Visual & -0.025 & 0.116 & 0.000 \\
\hline & Sequential & -0.03 & -0.003 & 0.113 \\
\hline
\end{tabular}


Although the three performance measures were not significantly correlated with each other (presentation score and score for group work: $\mathrm{r}=0.131$, presentation score and report score: $\mathrm{r}=0.037)$, the score for group work and presentation score are slightly correlated $(\mathrm{r}=0.155$, $\mathrm{p}=0.056$ ). The discussion about which factors directly affect these three performances are as follows.

(1) As shown in Table 2, higher individual score for group work were associated with higher levels of perceived self-efficacy, intrinsic value and the use of assimilation strategy and effort management. A regression analysis $(\mathrm{R}=0.247)$ reveals that individual score for group work were directly positively related to perceived intrinsic value only. This suggests that the higher intrinsic value of the course a learner perceived, the better performance she/he had in group work.

(2) Higher individual presentation score was only associated with higher levels of self-efficacy and higher level of active learning style. Regression analysis of individual presentation $(\mathrm{R}=0.324)$ reveals that individual presentation score was directly positively related to both self-efficacy and active dimension of learning style. This suggests that the higher self-efficacy a learner perceived, the better performance she/he may get in the presentation task and the stronger active preferences identified by ILS a learner had, the better performance she/he may had in the presentation task.

(3) Higher individual report score was only associated with higher level of sensing learning style. This suggests that the stronger sensing preferences identified by ILS a learner had, the better performance she/he may had in the task which requiring describing what she/he learn from other presenters and how to improve her/his own group work.

\subsection{Gender Differences in Learning Performance}

The second research question concerns if the gender differences affected the learning individual performance in the cooperative course. Table 3 displays the t-test results of the learning performance of the male and female students. There were significant gender differences in the individual score for group work and in the score of individual report, but no in the presentation score. This suggests that compared to male students, the female students may have a better performance on group work and on assignments that require reflection although they do not differ on the presentation performance.

Table 3: The ANOVA result of gender differences in individual learning performance

\begin{tabular}{lllllll} 
& Gender & $\mathrm{N}$ & Mean & $\mathrm{SD}$ & Levene's Test & ANOVA \\
\hline \multirow{2}{*}{$\begin{array}{l}\text { Score for } \\
\text { group work }\end{array}$} & female & 101 & 43.95 & 8.97 & sig=0.278 & $\mathrm{F}=4.093^{*}$ \\
\hline \multirow{2}{*}{ Presentation } & 56 & 46.75 & 6.99 & & $\mathrm{Sig}=0.045$ \\
& male & 98 & 31.89 & 2.81 & sig=0.187 & $\mathrm{F}=0.701$ \\
& female & 55 & 32.27 & 2.26 & & $\mathrm{Sig}=0.404$ \\
\hline \multirow{2}{*}{ report } & male & 98 & 3.76 & 0.93 & sig=0.938 & $\mathrm{F}=4.662 *$ \\
& female & 55 & 4.09 & 0.91 & & $\mathrm{Sig}=0.032$ \\
\hline & & & & & & $* \mathrm{p}<.05$
\end{tabular}




\section{Predict Group Performance and its Application to the Group Formation Problem}

\subsection{Formulations for Predicting Group Performance}

In literature, the goodness of group formation is normally defined based on the heterogeneity or homogeneity of group members' attributes [10] [14] [15]. Davidson [35] claims when a task requires the group members to working on a specific skill, procedure or set of facts, homogeneous groups can enable instructors to address the problems of learners according to their ability level; when a task requires the group members to working on open-ended problems and learn how to communicate, heterogeneous groups can encourage learners with different abilities to contribute for potential solutions without caring about their ability because of the exiting of more than one correct answer. Since the tasks given in the target course in this study are open-ended problems and the goal of target course is encouraging the development of communication skill, the relation between group performance and the heterogeneity of group members' attributes is examined.

To obtain heterogeneous groups, Graf and Bekele [10] had proposed a math model considering the mean, minimum and maximum of all the learner attributes as group variables. In this paper we propose to only take into account the learner attributes, which directly related to learning performances according to the learning analysis results, for the further calculation of group variables. Since the group formation approach considering too many learners attributes will drastically increase computation time, making use of learning analytic technique, the attributes, which directly related to learning performance, could be identified; analysis results can exclude uncorrelated attributes and reduce the amount of the attributes in the calculation of grouping formation. In other word, if the scores of each group could be predicted based on some attributes of the group members, in practical the group learning performance could be enhanced by adjusting the grouping.

According to Table 2, perceived self-efficacy, intrinsic value, the use of assimilation strategy and effort management, and the levels of active and sensing learning styles, these five learner attributes should be use for further group variables calculation due to their significant correlation with learning performance. Table 4 shows the correlation between those group variables and group performance ( 5 or 6 students per groups, 28 group in total). The use of retrieval strategy, visual and sequential learning styles are not considered here for the calculation of group variables since these three attributes were uncorrelated with any individual learning performance in this cooperative course as described in Table2.

Table 4: The Pearson correlation between group variables and group performance

\begin{tabular}{llllll}
\hline & Self-Efficacy & $\begin{array}{c}\text { Intrinsic } \\
\text { Value }\end{array}$ & $\begin{array}{c}\text { Assimilation and } \\
\text { effort management }\end{array}$ & Active & Sensing \\
\hline $\mathrm{M}$ & 0.147 & $0.585^{* *}$ & 0.322 & 0.100 & 0.009 \\
\hline $\operatorname{Min}$ & $0.632^{* *}$ & $0.406^{* *}$ & 0.118 & -0.007 & 0.043 \\
\hline $\operatorname{Max}$ & $0.490^{* *}$ & $0.531^{* *}$ & 0.312 & 0.365 & 0.239 \\
\hline & & & & $*^{* *}<<.01$ and $\mathrm{N}=28$.
\end{tabular}


Assumed the amount of each class is $\mathrm{N}$ and learners $\left\{\mathrm{L}_{1}, \mathrm{~L}_{2}, \ldots, \mathrm{L}_{\mathrm{N}}\right\}$ are supposed to be distributed into $M$ groups $G_{1}, G_{2}, \ldots, G_{M}$, then the member amount of each group $K=N / M$. According to conclusion of the second research question, female students had significantly better learning performance in group working. The percentage of female member in a group is also considered. In summary, the percentage of female member and the 15 group variables in Table 4 are considered in a regression analysis on group performances (the sum of group total report scores).

The stepwise regression result $(\mathrm{R}=0.824$, $\mathrm{R}$ square $=0.679$, Adjusted $\mathrm{R}$ square $=0.623$ ) suggests the following formulation for prediction of the group performance (the predicted scores of group $\mathrm{Gi}$ is $\mathrm{S}(\mathrm{Gi})$ ):

$$
\begin{gathered}
\mathrm{S}\left(\mathrm{G}_{\mathrm{i}}\right)=12.079+4.284 \mathrm{Min}\left(\text { Self-Efficacy }\left[\mathrm{G}_{\mathrm{i}}\right]\right)+8.023 \mathrm{M}\left(\text { IntrinsicValue }\left[\mathrm{G}_{\mathrm{i}}\right]\right)- \\
\text { 3.384Min }\left(\text { AssimilationStrategy }\left[\mathrm{G}_{\mathrm{i}}\right]\right)-1.406 \mathrm{Min}\left(\text { Active }\left[\mathrm{G}_{\mathrm{i}}\right]\right)(1)
\end{gathered}
$$

where $\mathrm{M}(\mathrm{A}[\mathrm{Gi}])$, $\operatorname{Min}(\mathrm{A}[\mathrm{Gi}])$, and $\operatorname{Max}(\mathrm{A}[\mathrm{Gi}])$ represent the mean, minimum, and maximum values of the attribute $\mathrm{A}$ for group $\mathrm{Gi}$.

By contrast, the backward regression result $(\mathrm{R}=0.893$, $\mathrm{R}$ square $=0.798$, Adjusted $\mathrm{R}$ square $=0.727$ ) suggests the following formulation for prediction of the group performance:

$$
\begin{gathered}
\mathrm{S}\left(\mathrm{G}_{\mathrm{i}}\right)=-23.502+3.952 \mathrm{Min}\left(\text { Self-Efficacy }\left[\mathrm{G}_{\mathrm{i}}\right]\right)+2.677 \mathrm{Min}\left(\text { IntrinsicValue }\left[\mathrm{G}_{\mathrm{i}}\right]\right) \\
+ \text { 3.094Max }\left(\text { IntrinsicValue }\left[\mathrm{G}_{\mathrm{i}}\right]\right)+10.744 \mathrm{M}\left(\text { AssimilationStrategy }\left[\mathrm{G}_{\mathrm{i}}\right]\right)- \\
\text { 3.384Min(AssimilationStrategy } \left.\left[\mathrm{G}_{\mathrm{i}}\right]\right)-2.240 \mathrm{Min}\left(\text { Active }\left[\mathrm{G}_{\mathrm{i}}\right]\right)+1.650 \mathrm{Max}\left(\operatorname{Sensing}\left[\mathrm{G}_{\mathrm{i}}\right]\right)
\end{gathered}
$$

Although there may be other factors that affect the group performance, the regression model suggested by formula 1 , can be used to explain $62.3 \%$ of the observed group performance data; while the regression model suggested by formula 2 , can be used to explain $72.7 \%$ of the observed group performance data. Formula 1 and formula 2 both involve three group variables: $\operatorname{Min}\left(\right.$ Self-Efficacy $\left[\mathrm{G}_{\mathrm{i}}\right]$ ) and $\operatorname{Min}\left(\right.$ AssimilationStrategy[ $\left.\mathrm{G}_{\mathrm{i}}\right]$ ) and $\operatorname{Min}\left(\right.$ Active$\left.\left[\mathrm{G}_{\mathrm{i}}\right]\right)$. Formula 2 with higher $R$ value requires the calculation on 5 attributes of group members ( 7 variables in total); besides the 4 attributes (self-efficacy, intrinsic value assimilation strategy and effort management strategy, and active learning style) of group members required in the calculation of formula 1 (4 variables in total), each group member's learning style indicator in sensing dimension is also required in formula 2.

In future, more analysis will be conducted on learner data for other subtopic of this course to explore the robustness of these two formulas. Finally, the one with higher robustness will be determined for the model presented next. No matter which formula is determined, requiring the calculation on 4 or 5 learner attributes, sharply decreases the workload compared to considering all the 8 attributes described in table 2 .

\subsection{An Adjustable Model to Find Optimum Solution of Group Formation}

As discussed in the introduction, when multiple attributes of learners are considered, identifying good ones among vast grouping candidates generally becomes complicated. This group formation problem is often regarded as an optimization problem with discrete variables. Typical 
approach is exploring the optimum of the grouping solution through maximization of an objective function that measures the goodness of a group formation [7] [8] [9] [10] [11]. Along this approach, in our study, we can construct the objective function in response to teaching strategies by using the prediction formula for group performance as follows.

(1) If the teaching goal is to pursuit maximizing the average value of all the groups' score, then $\mathrm{S}_{\text {mean }}=\Sigma_{\mathrm{i}} \mathrm{S}\left(\mathrm{G}_{\mathrm{i}}\right) / \mathrm{M}$ is regarded as the objective function of the group formation. The optimum solution of the group formation could be done if the grouping whose attributes maximize of Smean can be found.

(2) If the teaching goal is to pursuit the homogeneous of all the groups' scores, then

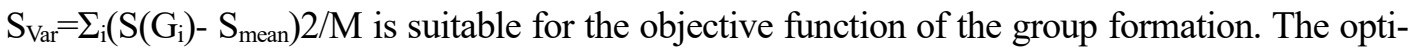
mum solution of group formation could be done if the grouping whose attributes minimize $\mathrm{S}_{\mathrm{Var}}$ is found.

(3) If the teaching goal is to pursuit both the average value maximization and the homogeneous of all the groups' scores, then the objective function can be considered as the following mixed type function:

$$
\mathrm{S}_{\mathrm{mix}}=\mathrm{c} 1 * \mathrm{~S}_{\mathrm{mean}}-\mathrm{c} 2 * \mathrm{~S}_{\mathrm{Var}}
$$

Here $\mathrm{c} 1$ and $\mathrm{c} 2$ are positive coefficients, which should be set as suitable values. The optimum solution of the group formation could be done if the grouping whose attributes maximize Smix can be found.

The next step of the study is to develop a tool that implements an adjustable mathematical model, which allow the instructor to determine one of the teaching strategies mentioned above. A series of experiment will be conducted to compare the model under three proposed teaching strategies using real-world data. The performance effectiveness and robustness are expected to be evaluated.

\section{Conclusion}

In this paper, based on the analysis of learner characteristics measured in the real-world, the prediction of group performance for the group formation is formulated. Firstly, it is found that perceived self-efficacy, intrinsic value, the use of assimilation strategy and effort management, and the levels of active and sensing learning styles, these five learner attributes are related to the individual performances in the cooperative course. Secondly, the results of further (stepwise and backward) regression analysis on group learning performance suggest two formulas for predicting the group performance. Further analysis work on learner data collected from other topics of this course will be conducted to explore the robustness of these two formulas for predicting group performance. Finally, using the prediction formula with better robustness, we present mathematical models for forming groups of learners under different teaching strategies. To sum up, for the evaluation of the goodness of a group formation, the objective function adopts the formulation suggested by real-world data analysis results to predict the group scores.

The limitation of this study is that the analyses only focus on the relation between group performance and four aspects of member attributes (learning motivation, learning strategy, 
learning style and gender) due to the specific goal of the target course which requires group members working on open-end problem-solving tasks. Although the Adjusted R-squared of the formulas 1 and 2 suggests that the majority of the group performance variance (more than $60 \%$ ) can be predicted. However, human learning behaviors are complicated, and these may be other factors that affect the group performance. Further learner data should be collected and analyzed to explore the robustness of these two formulas.

In the future, we will implement a tool based on an adjustable mathematical model to support daily teaching of "Interdisciplinary collaborative learning of Social Issues" course. One input of this tool is the learner characteristics (learning motivation, learning strategy and learning style) data which should be collected before the grouping. Another input of the tool is the teaching strategy (pursuit maximizing the average value of all the groups' score, pursuit the homogeneous of all the groups' scores, or pursuit both the average value maximization and the homogeneous of all the groups' scores) which needs to be determined by the instructor. With these two inputs, the tool making use of the formula predicted by this study, will automatically suggest the grouping candidates to maximize the learning outcome in response to the teaching strategy. A series of experiments will be conducted to study the effectiveness of this tool.

\section{Acknowledgement}

The research is supported by JSPS KAKENHI Grant No. 17K17936, KAKENHI Grant No. 16K16173).

\section{References}

[1] J. E. Camara, B. N. Carr, \& B. L. Grota, "One approach to formulating and evaluating student work groups in legal environment of business courses," Journal of Legal Studies Education, 24(1), 2007, pp.1-18.

[2] D. H. Jonassen, \& H. I. Kwon, "Communication patterns in computer-mediated and face-to-face group problem-solving," Educational Technology Research and Development, 49(1), 2001, pp. 35-51.

[3] J. I. Tutty, \& J. D. Klein, "Computer-mediated instruction: a comparison of online and face-to-face collaboration," Educational Technology Research and Development, 56(2), 2008, pp.101-124.

[4] P. H. Miller, "Vygotsky's theory and the contextualists", Theories of developmental psychology, R. C. Atkinson, G. Lindzey, \& R. F. Thompson, eds., New York: W. H. Freeman and Company, 1993, pp. 368-423.

[5] M. Huxland, \& R. Land, "Assigning students in group work projects: can we do better than random?” Innovations in Education and Training International, 37 (1), 2000, pp.17-22.

[6] J. W. Li, Y. T. Wang, \& Y. C. Chang, "The Differences between Self-Organized Group and Designated Group for Cooperative Learning," 7th International Conference on Ubi-Media Computing and Workshops, 2014, DOI: 10.1109/U-MEDIA.2014.63. 
[7] G.J. Hwang, P.Y. Yin, C.W. Hwang, \& C.C. Tsai, "An Enhanced Genetic Approach to Composing Cooperative Learning Groups for Multiple Grouping Criteria," Journal of Educational Technology \& Society, 11(1), 2008, pp.148-167.

[8] J. Moreno, D.A. Ovalle, and R.M. Viccari, "A genetic algorithm approach for group formation in collaborative learning considering multiple student characteristics," Computers and Education, 58, 2012, pp. 560-569.

[9] W.M. Cruz, S. Isotani, "Group Formation Algorithms in Collaborative Learning Contexts: A Systematic Mapping of the Literature", Collaboration and Technology, LNCS 8658, N. Baloian, F. Burstein, H. Ogata, F. Santoro, G. Zurita, eds., Springer, Cham, 2014, pp.199-214.

[10] S. Graf, and R. Bekele, "Forming Heterogeneous Groups for Intelligent Collaborative Learning Systems with Ant Colony Optimization", Intelligent Tutoring Systems, LNCS 4053, M. Ikeda, K.D. Ashley, T.-W. Chan, eds., Springer, Heidelberg, 2006, pp.217-226.

[11] Y.-T. Lin, Y.-M. Huang, S.-C. Cheng, "An automatic group composition system for composing collaborative learning groups using enhanced particle swarm optimization," Computers \& Education, 55 (4), 2010, pp.1483-1493.

[12] C.-C. Liu, and C.-C. Tsai, "An analysis of peer interaction patterns as discoursed by on-line small group problem-solving activity," Computers \& Education, 50 (3), 2008, pp.627-639.

[13] Y. Taniguchi, Y. Gao, K. Kojima, S. Konomi, "Evaluating Learning Style-Based Grouping Strategies in Real-World Collaborative Learning Environment,". Distributed, Ambient and Pervasive Interactions: Technologies and Contexts (DAPI 2018), LNCS 10922, N. Streitz, S. Konomi, eds., Springer, Cham, 2018, pp. 227-239.

[14] S. Allan, "Grouping and the gifted ability-grouping research reviews: What do they say about grouping and the gifted? "Educational Leadership, 48(6), 1991, pp.60-65.

[15] S. B. Watson, \& J. E. Marshall, "Effects of cooperative incentives and heterogeneous arrangement on achievement and Interaction of cooperative learning groups in a college life science course," Journal of Research in Science Teaching, 32(3), 1995, pp.291-299.

[16] H. W. Marsh, "The big-fish-little-pond effect of academic self-concept," Journal of Educational Psychology, 79, 1987, pp. 280-295.

[17] N. M. Schullery, \& S. E. Schullery, "Are heterogeneous or homogeneous groups more beneficial to students? Journal of Management Education,” 30(4), 2006, pp. 542-556.

[18] K. Welner, \& R. Mickelson, "School reform, politics and tracking: Should we pursue virtue?” Educational Researcher, 29(4), 2000, pp. 22-26.

[19] M. Scherer, "On savage inequalities: A conversation with Jonathan Kozol," Educational Leadership, 50, 1993, pp. 4-9.

[20] M. Guralnick, "A hierarchical model of understanding children's peer-related social competence,". Social competence of young childrenwith disabilities: Issues and strategies for intervention, S.L. Odom, S.R. McConnell \& M.A. McEvoy, eds., Baltimore: Paul H. 
Brookes, 1992, pp. 37-64.

[21] T. Pica, \& C. Doughty, "The role of group work in classroom second language acquisition," Studies in Second Language Acquisition, 7, 1985. pp. 233-246.

[22] P. Porter, "How learners talk to each other: Input and interaction in task-centered discussions," Talking to learn: Conversation in second language acquisition, R. Day ed., Rowley, MA: Newbury House, 1986.

[23] S. Cotterall, "Developing reading strategies through small-group interaction," RELC Journal, 21, 1990, 55-69.

[24] R. R. Pintrich, and E. V. DeGroot, "Motivational and self-regulated learning components of classroom academic performance," J. Educational Psychology, 82, 1990, pp. 33-40.

[25] F. Coffield, D. Moseley, E. Hall, and K. Ecclestone, Learning styles and pedagogy in post-16 learning: A systematic and critical review, London: Learning and Skills Research Centre, 2004.

[26] H. Pashler, M. McDaniel, D. Rohrer, and R. Bjork, "Learning styles: Concepts and evidence," Psychological Science in the Public Interest, 9(3), 2009, pp. 105-119.

[27] R.M. Felder and E.R. Henriques, "Learning and Teaching Styles in Foreign and Second Language Education. Foreign Language Annals," 28 (1), 1995, pp. 21-31.

[28] R.M. Felder and J.E. Spurlin, "Applications, Reliability, and Validity of the Index of Learning Styles,” Intl. Journal of Engineering Education, 21(1), 2005, pp.103-112.

[29] J.Y. Wang, \& T. Mendori, "The Reliability and Validity of Felder- Silverman Index of Learning Styles in Mandarin Version," Information Engineering Express, 1(3), 2015, pp. 1-8.

[30] G. A. Livesay, K. C. Dee, E. A. Nauman and L. S., Jr. Hites, "Engineering student learning styles: a Statistical Analysis Using Felder's Index of Learning Styles," Conference of the American society for engineering education 2002, Montreal, Quebec, 2002.

[31] N. V. Zwanenberg, L J. Wilkinson, \& A. Anderson, "Felder and Silverman's Index of Learning Styles and Honey and Mumford's Learning Styles Questionnaire: How do they compare and do they predict academic performance?” Educational Psychology, 20 (3), 2000, pp. 365-381.

[32] M.S. Zywno, "A Contribution to Validation of Score Meaning for Felder Soloman's Index of Learning Styles," Proceedings of the 2003 ASEE Annual Conference, ASEE, 2003.

[33] B.W. Tuckman, Conducting Educational Research, 5th edition, Belmont, CA: Wadsworth Group, 1999.

[34] E. Aronson, and S. Patnoe, "The jigsaw classroom: building cooperation in the classroom," 2nd edn, Addison Wesley Longman, New York, 1997.

[35] N. Davidson, Cooperative Learning in Mathematics: A Handbook for Teachers, Menlo Park, CA: Addison-Wesley, 1990. 